\title{
Molecular Detection and Antibiogram of ESBL-Producing and Carbapenem- Resistant Escherichia coli from Rabbit, Swine, and Poultry in Malaysia
}

\author{
M. H. Chai ${ }^{a}$, M. Z. Sukimana, N. Jasmya , N. A. Zulkiflya , N. A. S. Mohd Yusof ${ }^{a}$, N. M. Mohamad ${ }^{b}$, \\ S. M. Z. Ariffin' ${ }^{c}$ \& M. F. Ghazali ${ }^{a, *}$ \\ aSchool of Animal, Aquatic and Environmental Sciences, Faculty of Bioresources and Food Industry, \\ Universiti Sultan Zainal Abidin, Besut Campus, 22200, Besut, Terengganu, Malaysia \\ ${ }^{\mathrm{b}}$ Centralised Laboratory Management Centre, Universiti Sultan Zainal Abidin \\ Besut Campus, 22200, Besut, Terengganu, Malaysia \\ 'Department of Veterinary Pre-Clinical Sciences, Faculty of Veterinary Medicine, Universiti Putra Malaysia \\ 43400, Serdang, Selangor, Malaysia \\ *Corresponding author: faizalghazali@unisza.edu.my \\ (Received 23-01-2021; Revised 27-04-2021; Accepted 03-05-2021)
}

\begin{abstract}
The emergence of multidrug-resistance Enterobacteriaceae such as extended-spectrum $\beta$-lactamase (ESBL) producing Escherichia coli (E. coli) and carbapenem-resistant E. coli (CREC) has become an urgent veterinary and public health threat. These multidrug-resistant microorganisms are frequently associated with diseases that have high mortality with limited treatment options. This study aims to investigate the prevalence of ESBL producing E. coli and CREC from the rabbit, swine, and poultry and to determine the antibiogram profile of these E. coli isolates. In this study, 400 fecal swab samples were collected from rabbits, swine, and poultry from several selected animal farms in Malaysia. After incubation and isolation processes, suspected $E$. coli isolates were subjected to a PCR test to confirm the identity of the bacteria. The antibiogram of the $E$. coli isolates was determined via the Kirby Bauer disk diffusion method. A total of 212 (53\%) E. coli isolates were isolated from rabbits (51 isolates), poultry (110 isolates), and swine (51 isolates). Screening of antimicrobial resistance genes revealed twelve ESBL producing E. coli $(3 \% ; 12 / 400)$. Two ESBL producing E. coli were also carrying carbapenemase gene $\left(B l a_{N D M}\right)$, indicating ESBL producing and carbapenem-resistant $E$. coli (ESBL-CREC) in poultry fecal swab samples. The bacteria isolates were found to show resistance against nine antibiotics, including ertapenem, ampicillin, and amoxicillin-clavulanate. A total of $3.3 \%(7 / 212)$ of the $E$. coli isolates were found to be multidrug-resistance. This study demonstrated the presence of ESBL-producing E. coli and ESBL-producing CREC from poultry fecal swabs in Malaysia.
\end{abstract}

Keywords: carbapenem-resistant Escherichia coli (CREC); extended-spectrum $\beta$-lactamase (ESBL); antibiotic resistance; antibiogram; livestock

\section{INTRODUCTION}

The widespread of microorganisms with antimicrobial resistance traits are recognized as serious threats to human and animal health globally (Tian et al., 2018; Chai et al., 2020). These concerns are exemplified by the emergence of Gram-negative bacteria that show multidrug-resistance traits. Similar to the other commensal bacteria, E. coli can be commonly found in humans, animals, and the environment, making them an excellent indicator of antimicrobial resistance. Globally, antibiotic resistances were frequently detected among commensal bacteria from food-producing animals (Ramos et al., 2020). The use of critically important antibiotics in food-producing animals has led to the emergence of multidrug-resistant foodborne bacteria, including extended-spectrum $\beta$-lactamase (ESBL)-producing E. coli (Ramos et al., 2020). ESBL-producing E. coli can release
ESBL enzymes to hydrolyze all $\beta$-lactams, including the third generation of cephalosporins, except cephamycin and carbapenems (Kpoda et al., 2018). In fact, many ESBL-producing E. coli are also resistant to the other antimicrobial groups, such as aminoglycosides, fluoroquinolones, and trimethoprim-sulfamethoxazole (Abayneh et al., 2018).

Carbapenems having a broad-spectrum antibacterial activity are the most effective $\beta$-lactams antibiotics against Gram-positive and Gram-negative bacteria. For years, carbapenems have been considered the most effective antibiotic to treat serious infections caused by multidrug-resistant Gram-negative bacteria (Liu et al., 2018). The mode of action of carbapenem is initiated by penetration of the bacterial cell wall and binding to enzymes known as penicillin-binding protein (PBPs). The resultant lethal effect is the inactivation of an inhibitor of autolytic enzymes within the cell wall, which will lead 
to the killing of bacteria (Codjoe \& Donkor, 2017). The presence of a carbapenem structure with the $\beta$-lactam ring allows the carbapenems to be less vulnerable to most $\beta$-lactam resistance determinants. Besides, carbapenems present fewer adverse effects to the patients, making them a safer therapeutic choice than the other last-line antibiotics. However, the rapid increase in the prevalence rate of carbapenemase gene carriage by Enterobacteriaceae has render carbapenems useless against such pathogens (Codjoe \& Donkor, 2017).

Briefly, resistance to carbapenems can be brought about by various mechanisms, with the most common being the production of carbapenemases, a class of enzymes capable of degrading carbapenems (Sawa et al., 2020). Besides, resistance to carbapenems can also be due to the poor binding of carbapenems to penicillinbinding proteins present in the bacteria, the overexpression of multidrug efflux pumps by the bacteria or lack of porins present in the bacterial cell membrane (Suay-García \& Pérez-Gracia, 2019). In fact, carbapenemresistant Enterobacteriaceae (CRE) bacteria such as carbapenem-resistance E. coli (CREC) do not respond to common antibiotics and thus limit the treatment options (Köck et al., 2018). Hence, the emergence of antibiotic resistance in Enterobacteriaceae has significant clinical and socioeconomic consequences (Rodríguez-Baño et al., 2018).

Previous studies reported the presence of ESBLproducing E. coli and CREC in food-producing animals (Köck et al., 2018; Hosuru Subramanya et al., 2020). However, little is known regarding the spread of ESBLproducing E. coli and CRE among livestock animals in Malaysia. Therefore, this study aims to determine the prevalence rates of ESBL-producing E. coli and CREC as well the antibiogram profile of $E$. coli isolated from commercially farmed rabbits, swine, and poultry in Malaysia. Subsequently, the findings from this study shall provide useful insights into the development of strategies to treat and control the spread of multidrugresistance $E$. coli in livestock.

\section{MATERIALS AND METHODS}

\section{Ethical Approval}

The study and sampling method were approved by the Universiti Sultan Zainal Abidin Animal and Plant Research Ethnic Committee (UAPREC) under the code: UAPREC/04/018.

\section{Sample Collection and E. coli Isolation}

A total of 400 fecal swab samples of 100 rabbits, 100 swine, and 200 poultry were collected from various commercial farms and abattoirs in Malaysia. All of the samples were independently collected by swab technique through rectal using sterilized cotton swabs. The fecal samples collected were then placed in the transport media, Brilliant Green Bile broth (HiMedia, India), and incubated at $37{ }^{\circ} \mathrm{C}$ for 24 hours. After incubation, the swab samples were streaked onto eosin-methylene blue (EMB) agar plates (Merck KGaA, Germany) and incubated at $37{ }^{\circ} \mathrm{C}$ for 24 hours. Bacterial colonies that showed metallic green sheen appearance on EMB were collected and streaked on Muller Hinton Agar (MHA) plates (Oxoid LTD, UK). The suspected bacteria colonies were then subjected to phenotypic identification. The selected bacteria colonies from MHA were tested with Gram staining and several biochemical tests, including Catalase and Triple Sugar Iron (TSI) agar tests. Isolates that were Gram-negative, rod-shaped, and showed biochemical characteristics identical to $E$. coli were further analyzed using genotypic approaches.

\section{Genotypic Identification of E. coli and CREC}

The genomic DNA of the bacterial isolates was extracted using the simple boiling method described by Rasool et al. (2018). The bacterial isolates were identified using primers that detected 16S rRNA of E. coli (Mogheiseh et al., 2020). Isolates that showed the presence of DNA bands on $2.0 \%(\mathrm{w} / \mathrm{v})$ agarose gel (Promega, USA) at the size of $232 \mathrm{bp}$ were considered to be E. coli, as shown in Figure 1. E. coli isolates were then further subjected to PCR test to screen for the presence of antimicrobial resistance genes using the primers listed in Table 1. E. coli isolates that harbored bla ${ }_{\text {CTX-M1 }}$ gene were categorized as ESBL-producing E. coli. E. coli isolates that tested positive for $b l a_{N D M^{\prime}} b l a_{O X A^{\prime}} b l a_{K P C^{\prime}}$ and bla $a_{V I M}$ were considered as CREC.

\section{Antibiogram}

An antibiotic susceptibility test was performed on the E. coli isolates using the Kirby-Bauer disk diffusion method. The susceptibility of the E. coli isolates against antimicrobial agents was tested using 11 different antibiotic discs, including doripenem $(10 \mu \mathrm{g})$, ertapenem $(10 \mu \mathrm{g})$, imipenem $(10 \mu \mathrm{g})$, meropenem $(10$ $\mu \mathrm{g})$, amoxicillin-clavulanate $(10 \mu \mathrm{g})$, ampicillin $(10 \mu \mathrm{g})$, tetracycline $(30 \mu \mathrm{g})$, doxycycline $(30 \mu \mathrm{g})$, gentamicin $(10$ $\mu \mathrm{g})$, and ciprofloxacin $(5 \mu \mathrm{g})$. Two duplicates were made for each isolate, and the MHA plates inoculated with $E$. coli were incubated at $37^{\circ} \mathrm{C}$ for 24 hours. The diameter of inhibition zones was measured, and the results were interpreted based on the Clinical and Laboratory Standards Institute (CLSI) standard guidelines (CLSI, 2018). Isolates that showed resistance against 3 or more categories of antibiotics were classified as multidrugresistant E. coli (Magiorakos et al., 2012).

\section{Data Analysis}

The prevalence rate of E. coli, ESBL producing E. coli, and CREC were calculated and presented in percentage $(\%)$. Categorical data were analyzed using Chi-square test or Fisher's exact tests via Minitab® 16.1.1 (2010) with 95\% confidence interval $(p<0.05)$ was set to indicate the significant difference. The antibiotic resistance rates (\%) of the E. coli isolates were calculated as the proportion of isolates tested that had an inhibition zone below the respective antibiotic breakpoint. The 


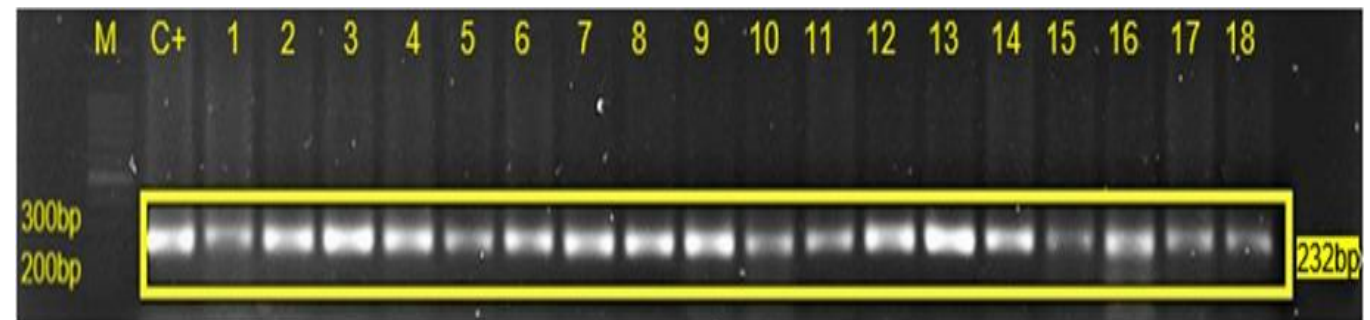

Figure 1. Agarose gel electrophoresis image of the 16 sRNA genes at the size of 232bp from representative isolates of Escherichia coli collected from fecal swab samples of chicken, pigs, and rabbits. Samples 1 to 18 were found to contain 16 sRNA genes and considered to be E. coli. $\mathrm{M}=100$ bp DNA marker; $\mathrm{C}+=$ positive control; 1 to $18=$ bacterial isolates from chicken, pigs, and rabbits.

Table 1. Primer sequences used in this study

\begin{tabular}{|c|c|c|c|c|}
\hline No. & Primers & Primer sequence $\left(5^{\prime}-3^{\prime}\right)$ & Base pair (bp) & References \\
\hline \multirow[t]{2}{*}{1} & 16S rRNA & ATCAACCGAGATTCCCCCAGT & 232 & Mogheiseh et al., 2020 \\
\hline & & TCACTATCGGTCAGTCAGGAG & & \\
\hline \multirow[t]{2}{*}{2} & $B l a_{C T X-M 1}$ & AAAAATCACTGCGCCAGTTC & 415 & Naas et al., 2011 \\
\hline & & AGCTTATTCATCGCCACGTT & & \\
\hline \multirow[t]{2}{*}{3} & $B l a_{N D M}$ & GGCCGTATGAGTGATTGC & 725 & Wang et al., 2012 \\
\hline & & TATTATGCACCCGGTCGC & & \\
\hline \multirow[t]{2}{*}{4} & $B l a_{O X A}$ & TTGGTGGCATCGATTATCGG & 744 & Brink et al., 2013 \\
\hline & & GAGCACTTCTTTTGTGATGGC & & \\
\hline \multirow[t]{2}{*}{5} & $B l a_{K P C}$ & СTGTCTTGTCTCTCATGGCC & 796 & Grundmann et al., 2017 \\
\hline & & CCTCGCTGTRCTTGTCATCC & & \\
\hline \multirow[t]{2}{*}{6} & $B l a_{V I M}$ & AGTGGTGAGTATCCGACAG & 212 & Grundmann et al., 2017 \\
\hline & & TCAATCTCCGCGAGAAG & & \\
\hline
\end{tabular}

relationships between antibiotic exposure and overall antibiotic resistance in $E$. coli isolates were assessed using multiple antimicrobial resistance index (MARI). The MARI was calculated as the proportion of antibiotics tested to which the isolate was phenotypically resistant (Rasool et al., 2018). A MARI index of 2.0 was set as a threshold value to differentiate low and highrisk regions where antibiotics were overused (Rasool et al., 2018). A dendrogram to visualize the relatedness between $E$. coli isolates based on their phenotypic antibiotic resistance was constructed using Unweighted Pair Group Method with Arithmetic Mean (UPGMA) in BioNumerics 8.0 software (Applied Maths, Texas).

\section{RESULTS}

\section{Genotypic Identification of E. coli and CREC}

The prevalence rate of $E$. coli, ESBL producing $E$. coli, and CREC from rabbit, swine, and poultry were summarized in Table 2. In this study, a total of 212 isolates of E. coli (53\%) were isolated from rabbit (51/100; $51 \%)$, swine $(51 / 100 ; 51 \%)$, and poultry $(110 / 200 ; 55 \%)$. Further screening of $b l a_{C T X-M 1}$ genes revealed the presence of $12(12 / 200 ; 5.5 \%)$ isolates of ESBL producing $E$. coli from poultry (Figure 2). Two CREC (1\%;2/200) were also identified among $E$. coli isolates from poultry fecal swab samples through screening of $b l a_{N D M}$ gene (Figure 3). No ESBL producing E. coli and CREC were detected from rabbits and swine.

\section{Antibiotic Susceptibility Test}

The antibiotic resistance rate of isolated E. coli $(n=212)$ against 11 different antibiotics was summarized in Table 3 and Table 4. Based on the antibiogram, the tested E. coli isolates showed resistance against nine different antibiotics, with a high resistance rate towards ertapenem $(48.1 \% ; 102 / 212)$. None of the $E$. coli was resistant against doripenem and imipenem. Further analysis revealed that $3.3 \%(7 / 212)$ of the $E$. coli isolates were categorized as multidrug resistance as they showed resistance to antibiotics from three different categories of antimicrobials. Additionally, 34\% (72/212) of E. coli displayed resistance behavior against agents from two different antibiotic groups, while 70 $(33 \%)$ isolates were only resistant to antibiotics from one category of antimicrobial. The MARI assessment (Table 5) revealed that $16(7.5 \% ; 16 / 212)$ isolates of $E$. coli had MARI values of 0.2 and above, where the isolates showed resistance against three and above antibiotics. The dendrogram generated using UPGMA, BioNumerics version 8.0 (Applied Maths, Texas) was shown in Figure 4.

\section{DISCUSSION}

The ongoing increase of antimicrobial resistance (AMR) among Gram-negative bacteria, especially Enterobacteriaceae in livestock animals, and their potential transmissions to humans represent a major 
Table 2. Prevalence rate of Escherichia coli, extended-spectrum $\beta$-lactamase (ESBL) producing E. coli, and carbapenem-resistant E. coli (CREC) according to animal species

\begin{tabular}{ccccc}
\hline Animal species & $\begin{array}{c}\text { Number of Escherichia coli } \\
\text { positive isolates }(\%)\end{array}$ & Significance & $\begin{array}{c}\text { Number of ESBL producing } \\
\text { Escherichia coli }(\%)\end{array}$ & Number of CREC $(\%)$ \\
\hline Rabbit & $51(51)$ & $\mathrm{p}>0.05$ & $0(0)$ & $0(0)$ \\
Swine & $51(51)$ & $\mathrm{p}>0.05$ & $0(0)$ & $0(0)$ \\
Poultry & $110(55)$ & $\mathrm{p}>0.05$ & $11(5.5)$ & $2(1)$ \\
\hline
\end{tabular}

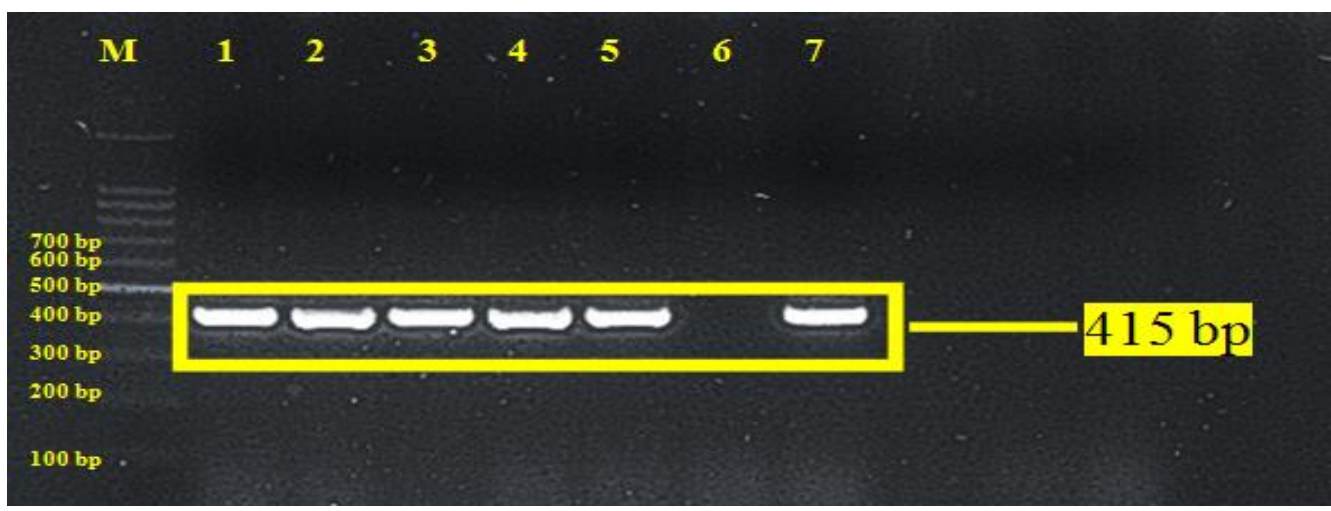

Figure 2. Agarose gel electrophoresis image of $b l a_{C T X-M 1}$ gene at the size of $415 \mathrm{bp}$ from representative isolates of Escherichia coli collected from rectal swab samples of chicken. E. coli isolates 1, 2, 3, 4, 5, and 7 were found to be $b l a_{C T X-M 1}$ genes positive and considered to be ESBL-producing E. coli. $\mathrm{M}=100 \mathrm{bp}$ DNA marker; 1 to 5 and $6=E$. coli isolates from chicken.

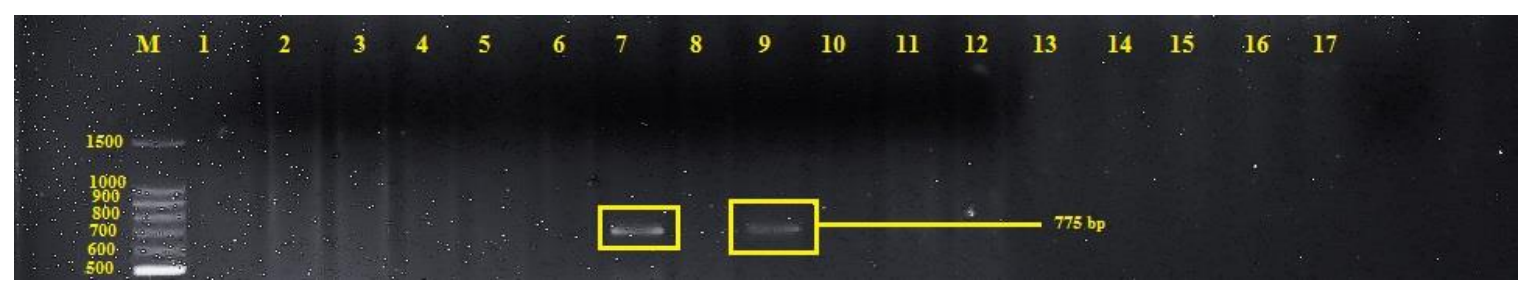

Figure 3. Agarose gel electrophoresis image of $b l a_{N D M}$ genes at the size of $775 \mathrm{bp}$ from eleven extended-spectrum $\beta$-lactamase (ESBL) producing Escherichia coli isolated in chicken. Bacterial isolates labeled 7 and 9 produced DNA band for $b l a_{N D M}$ genes at size approximately $775 \mathrm{bp}$. M= $100 \mathrm{bp}$ DNA marker; 1 to $11=$ ESBL-producing E. coli from chicken.

concern to public health. This is because the treatments of infections caused by AMR bacteria are much more challenging, with limited antibiotic options and limited evidence of their efficacy (Rodríguez-Baño et al., 2018). Commensal enteric bacteria, such as $E$. coli which reside for prolonged periods inside the intestinal tract, may act as reservoirs for AMR dispersion in the food chain (Lugsomya et al., 2018).

In the present study, the overall prevalence rate of $E$. coli from the three species of animals was $53 \%$ (212/400). The prevalence rate of E. coli found in this study is higher than the prevalence rate of $6.3 \%$ in swine, $15.7 \%$ in chicken, and $40 \%$ in rabbit samples reported elsewhere (Abd El Tawab et al., 2015; Eldin \& Reda, 2016; Zhang et al., 2019). Further genotypic screening of $b l a_{\mathrm{CTX}-\mathrm{M} 1}$ revealed the presence of ESBL-producing E. coli $(5.5 \%$; 11/200) from poultry fecal swab samples. This finding is lower than the $20.1 \%$ to $52.14 \%$ occurrence rates of ESBL-producing E. coli reported in chicken by previous studies elsewhere (Chishimba et al., 2016;
Rahman et al., 2018; Baran et al., 2020). In 2016, a study conducted by Chishimba et al. (2016) reported 20.1\% of the E. coli isolates from poultry swab samples collected in a poultry abattoir located in Lusaka, Zambia, were confirmed to be ESBL-producing E. coli. Another study by Rahman et al. (2019) reported that $47.6 \%$ of $E$. coli isolates recovered from chicken meats in live bird markets of District Peshawar, Pakistan, were found to be ESBL producers. Meanwhile, Baran et al. (2020) stated the prevalence of $52.1 \%$ ESBL-producing E. coli in broiler meats obtained from supermarkets in Erzurum, Turkey. In addition, two of the ESBL-producing E. coli isolates were harboring $b l a_{N D M}$ genes, indicating the presence of ESBL-producing CREC. This result is different from the study by Hosuru Subramanya et al. (2020) that reported the absence of carbapenemase-producing $E$. coli from rectal swab samples collected among healthy chickens in Kaski District of Western Nepal. The presence of ESBLproducing CRE is worrisome since isolates that harbor both ESBL and carbapenemase genes often confer a 
Table 3. Antibiogram of Escherichia coli against 11 selected antibiotics (n=212)

\begin{tabular}{clcccc}
\hline \multirow{2}{*}{ No } & \multirow{2}{*}{ Antibiotics } & \multirow{2}{*}{ Potency $(\mu \mathrm{g})$} & \multicolumn{3}{c}{ Number of isolates $(\%)$} \\
\cline { 4 - 6 } & & 10 & $102(48.1)$ & Intermediate & Susceptible \\
\hline 1 & Ertapenem & 10 & $51(24.1)$ & $0(0)$ & $110(51.9)$ \\
2 & Ampicillin & 10 & $27(12.7)$ & $20(9.4)$ & $161(75.9)$ \\
3 & Amoxicillin-clavulanate & 30 & $22(10.4)$ & $4(1.9)$ & $165(77.8)$ \\
4 & Tetracycline & 5 & $12(5.7)$ & $13(6.1)$ & $186(87.7)$ \\
5 & Ciprofloxacin & 30 & $6(2.8)$ & $2(0.9)$ & $187(88.2)$ \\
6 & Amikacin & 30 & $3(1.4)$ & $4(1.9)$ & $204(96.2)$ \\
7 & Doxycycline & 10 & $6(2.8)$ & $7(3.3)$ & $205(96.7)$ \\
8 & Meropenem & 10 & $4(1.9)$ & $2(0.9)$ & $199(93.7)$ \\
9 & Gentamicin & 10 & $0(0)$ & $3(1.4)$ & $206(97.2)$ \\
10 & Doripenem & 10 & $0(0)$ & $2(0.9)$ & $209(98.6)$ \\
11 & Imipenem & & & $210(99.1)$ \\
\hline
\end{tabular}

Table 4. Antibiogram of extended-spectrum $\beta$-lactamase (ESBL)-producing Escherichia coli against 11 selected antibiotics (n=12)

\begin{tabular}{clcccc}
\hline \multirow{2}{*}{ No } & \multirow{2}{*}{ Antibiotics } & \multirow{2}{*}{ Potency $(\mu \mathrm{g})$} & \multicolumn{3}{c}{ Number of isolates $(\%)$} \\
\cline { 3 - 5 } & & 5 & Resistant & Intermediate & Susceptible \\
\hline 1 & Ciprofloxacin & 10 & $3(25)$ & $2(16.7)$ & $7(58.3)$ \\
2 & Amoxicillin-clavulanate & 10 & $0(0)$ & $1(8.3)$ & $10(100)$ \\
3 & Ertapenem & 10 & $0(0)$ & $0(0)$ & $12(100)$ \\
4 & Ampicillin & 30 & $0(0)$ & $0(0)$ & $12(100)$ \\
5 & Tetracycline & 30 & $0(0)$ & $0(0)$ & $12(100)$ \\
6 & Amikacin & 30 & $0(0)$ & $0(0)$ & $12(100)$ \\
7 & Doxycycline & 10 & $0(0)$ & $0(0)$ & $12(100)$ \\
8 & Meropenem & 10 & $0(0)$ & $0(0)$ & $12(100)$ \\
9 & Gentamicin & 10 & $0(0)$ & $0(0)$ & $12(100)$ \\
10 & Doripenem & 10 & $0(0)$ & $12(100)$ \\
11 & Imipenem & & & $12(100)$ \\
\hline
\end{tabular}

Table 5. Multiple antimicrobial resistance index (MARI) assessment of Escherichia coli isolates $(\mathrm{n}=212)$

\begin{tabular}{cccc}
\hline $\begin{array}{c}\text { Number of } \\
\text { antibiotics }\end{array}$ & $\begin{array}{c}\text { Number of } \\
\text { isolates }\end{array}$ & $\begin{array}{c}\text { Percentages } \\
(\%)\end{array}$ & MARI \\
\hline 0 & 60 & 28.3 & $\mathbf{0}$ \\
1 & 67 & 31.6 & $\mathbf{0 . 0 9}$ \\
2 & 69 & 32.5 & $\mathbf{0 . 1 8}$ \\
3 & 13 & 6.1 & $\mathbf{0 . 2 7}$ \\
4 & 3 & 1.4 & $\mathbf{0 . 3 6}$ \\
\hline
\end{tabular}

higher resistance level to both carbapenem and cephalosporin (Tian et al., 2018). Nevertheless, it is important to note that the presence of these multidrug-resistant bacteria in food-producing animals as food contaminated with ESBL-producing and carbapenem resistance E. coli is a potential risk factor for their widespread dissemination in humans (Nahar et al., 2018).

Antibiotic-susceptibility testing revealed that isolated $E$. coli showed a relatively low resistance level against tested antibiotics, except for ertapenem (48.1\% resistance rate). This finding is different from the study carried by Yassin et al. (2017) that reported a low ertapenem resistance rate $(0.2 \%)$ by $E$. coli isolated from livestock in China. Since ertapenem belongs to the carbapenem group, the appearance of such a number of ertapenem-resistance E. coli (102/212) isolates suggested the emergence of carbapenem resistance $E$. coli. Bacteria that are resistant against carbapenem often produce carbapenemases, an enzyme that can inactivate carbapenems together with the other beta-lactam antibiotics and therefore called carbapenemases (Meletis, 2016). Some of the most effective and geographically widespread carbapenemases include KPC, VIM, NDM, OXA-48 types, and IMP (Meletis, 2016). Surprisingly, further genotypic screening of carbapenem resistance genes only detected the presence of bla ${ }_{\mathrm{NDM}}$ from two isolates. Other carbapenem resistance genes, such as bla ${ }_{\mathrm{OXA}^{\prime}}$ $b l a_{\mathrm{VIM}^{\prime}}$ or $b l a_{\mathrm{KPC}}$ genes, were not detected. It is possible that these ertapenem-resistant isolates may harbor the other resistance genes that were not tested in this study or recruited the other mechanisms to overcome the effect of carbapenem antibiotics. Thus, further investigation needs to be carried out to determine the possible mechanisms of resistance.

In this study, none of the E. coli isolates were resistant towards imipenem and doripenem, suggesting imipenem can be safely used to treat E. coli infections in swine, rabbit, and chicken. In addition, only a small portion of the isolates showed resistance against amikacin, doxycycline, meropenem, and gentamicin. It is noteworthy that the development of antimicrobial resistance in bacteria is frequently associated with the 


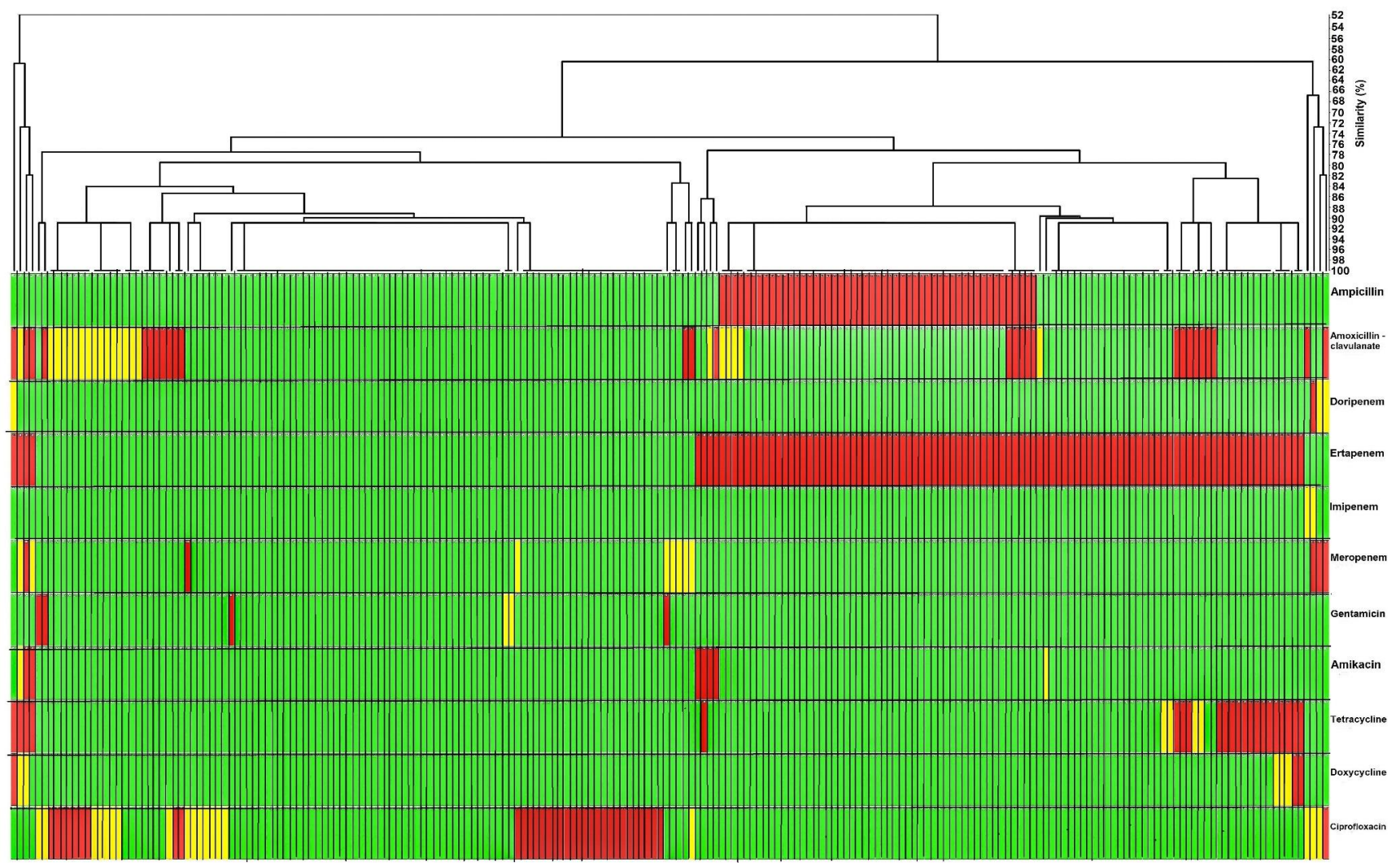

Figure 4. Dendrogram illustrating the relatedness of Escherichia coli isolates based on phenotypic antimicrobial resistance pattern (red= resistance; yellow= intermediate resistance, and green= susceptible).

repeated therapeutic or indiscriminate uses of antibiotics (Ariffin et al., 2019; Ariffin et al., 2020). Most of the antibiotics tested in this study were considered to be important critical antimicrobials (amikacin, meropenem, gentamicin, doripenem, and imipenem) and highly important antimicrobials (doxycycline) by World Health Organization (Scott et al., 2019). Therefore, the usage of these critically important antibiotics in livestock animals should be regulated to prevent further emergence of multidrug-resistance bacteria (Scott et al., 2019).

According to Magiorakos et al. (2012), multidrug resistance is defined as showing resistance to at least one agent in three or more antimicrobial categories. The present study showed that 3.3\% (7/212) of the isolates could be categorized as multidrug resistance. This finding is lower than the $50.9 \%$ prevalence rate of multidrug resistance $E$. coli reported in diarrhea rabbits from farms in Ningyang, Xintai, and Dongping regions of China (Zhao et al., 2018). Dendrogram generated using UPGMA also showed that the E. coli isolates from different species of animals appeared to show different antibiotic resistance patterns, suggesting these isolates may have different genetic backgrounds or exposure to different antibiotics. Further MARI assessment revealed that $16(7.5 \% ; 22 / 212)$ isolates of $E$. coli had MARI value of 0.2 and above, with resistance against three and above antibiotics. This result indicated that a small portion of the isolates was exposed to an environment with high antibiotic usage. Even though the number of E. coli isolates that showed resistance to multiple antibiotics is low, the veterinary authorities and farmers should be alerted to rationalize any usage of these antimicrobials in small and commercially producing livestock farms.

\section{CONCLUSION}

In this study, the overall prevalence of E. coli in fecal swab samples collected was 53\% (212/400). The presence of ESBL-producing E. coli and two ESBL-producing CREC were detected from poultry fecal swabs. The prevalence of resistance rate against antibiotics was relatively low, except for ertapenem (48.1\%; 102/212). The E. coli isolates did not display antibiotic resistance against imipenem and doripenem. In addition, 3.3\% (7/212) of the $E$. coli isolates were considered to be multidrug-resistance based on their phenotypic antibiotic resistance profiles.

\section{CONFLICT OF INTEREST}

None of the authors have any potential conflict of interest to declare.

\section{ACKNOWLEDGEMENT}

The authors thank the Research Acculturation Grant Scheme (RAGS) (Project code: RAGS/1/2015/SG0/ UNISZA/02/1) for funding this study. 


\section{REFERENCES}

Abayneh, M., G. Tesfaw, \& A. Abdissa. 2018. Isolation of extended-spectrum $\beta$ - lactamase-(ESBL-) producing Escherichia coli and Klebsiella pneumoniae from patients with community-onset urinary tract infections in Jimma University Specialized Hospital, Southwest Ethiopia. Can. J. Infect. Dis. Med. Microbiol. 2018:4846159. https://doi. org $/ 10.1155 / 2018 / 4846159$

Abd El Tawab, A. A., S. A. Abd El Aal, E. M. Mazied, \& D. A. EL Morsy. 2015. Prevalence of E. coli in broiler poultrys in winter and summer seasons by application of PCR with its antibiogram pattern. BVMJ 29:119-128. https://doi. org/10.21608/bvmj.2015.31683

Ariffin, S., N. Hasmadi, N. M, Syawari, M. Z. Sukiman, M. F. T. Ariffin, M. H. Chai, \& Ghazali, M. 2019. Prevalence and antibiotic susceptibility pattern of Staphylococcus aureus, Streptococcus agalactiae and Escherichia coli in dairy goats with clinical and subclinical mastitis. J. Anim. Health Prod. 7:32-37. https://doi.org/10.17582/journal. jahp/2019/7.1.32.37

Ariffin, M. F. T., N. Hasmadi, M.H. Chai, M. F. Ghazali, Z. Suhaili, \& S. M. Z. Ariffin. 2020. Prevalence and antimicrobial sensitivity pattern of Staphylococcus aureus isolated from clinical and subclinical mastitis in small ruminant in Besut and Setiu, Terengganu, Malaysia. Malays. J. Microbiol. 16:104-110. https://doi.org/10.21161/mjm.180328

Baran, A., M. C. Adigüzel, \& M. Yüksel. 2020. Prevalence of antibiotic-resistant and extended-spectrum beta-lactamaseproducing Escherichia coli in chicken meat from Eastern Turkey. Pak. Vet. J. 40:355-359. https://doi.org/10.29261/ pakvetj/2020.047

Brink, A. J., J. Coetzee, C. Corcoran, C. G. Clay, D. HariMakkan, R. K. Jacobson, G. A. Richards, C. Feldman, L. Nutt, J. van Greune, J. D. Deetlefs, K. Swart, L. Devenish, L. Poirel, \& J. D. Deetlefs. 2013. Emergence of OXA-48 and OXA-181 carbapenemases among Enterobacteriaceae in South Africa and evidence of in vivo selection of colistin resistance as a consequence of selective decontamination of the gastrointestinal tract. J. Clin. Microbiol. 51:369-372. https://doi.org/10.1128/JCM.02234-12

Chai, M. H., M. F. T. Ariffin, S. M. Z. Ariffin, Z. Suhaili, M. Z. Sukiman, \& M. F. Ghazali. 2020. Prevalence of methicillin resistant Staphylococcus aureus in raw goat milks from selected farms in Terengganu, Malaysia. Trop. Anim. Sci. J. 43:64-69. https://doi.org/10.5398/tasj.2020.43.1.64

Chishimba, K., B. M. Hang'Ombe, K. Muzandu, S. E. Mshana, M. I. Matee, C. Nakajima, \& Y. Suzuki. 2016. Detection of extended-spectrum beta-lactamase- producing Escherichia coli in market-ready chickens in Zambia. Int. J. Microbiol. 2016. https://doi.org/10.1155/2016/5275724

CLSI. 2018. Performance Standards for Antimicrobial Susceptibility Testing. 28th ed. CLSI supplement M100. Clinical and Laboratory Standards Institute, Wayne, PA.

Codjoe, F. \& E. Donkor. 2017. Carbapenem Resistance:A Review. Med. Sci. 6:1. https://doi.org/10.3390/medsci6010001

Eldin, W. F. S. \& L. M. Reda. 2016. Prevalence of diarrheagenic Escherichia coli in suckling rabbits. Jpn. J. Vet. Res. 64(Suppl. 2): S149-S153.

Grundmann, H., C. Glasner, B. Albiger, D. M. Aanensen, C. T. Tomlinson, A. T. Andrasević, R. Cantón, Y. Carmeli, A. W. Friedrich,C. G. Giske, \& Y. Glupczynski. 2017. Occurrence of carbapenemase-producing Klebsiella pneumoniae and Escherichia coli in the European survey of carbapenemase- producing Enterobacteriaceae (EuSCAPE): a prospective, multinational study. Lancet Infect. Dis. 17:153-163.

Hosuru Subramanya, S., I. Bairy, N. Nayak, R. Amberpet, S. Padukone, Y. Metok, D. R. Bhatta, \& B. Sathian. 2020.
Detection and characterization of ESBL- producing Enterobacteriaceae from the gut of healthy poultrys, Gallus gallus domesticus in rural Nepal: Dominance of CTX-M-15non-ST131 Escherichia coli clones. PLoS ONE 15:e0227725. https://doi.org/10.1371/journal.pone.0227725

Lugsomya, K., J. Yindee, W. Niyomtham, C. Tribuddharat, P. Tummaruk, D. J. Hampson, \& N. Prapasarakul. 2018. Antimicrobial resistance in commensal Escherichia coli isolated from swines and pork derived from farms either routinely using or not using in-feed antimicrobials. Microb. Drug Resist. 24:1054-1066. https://doi.org/10.1089/ mdr.2018.0154

Köck, R., I. Daniels-Haardt, K. Becker, A. Mellmann, A W. Friedrich, D. Mevius, S. Schwarz, \& A. Jurke. 2018. Carbapenem-resistant Enterobacteriaceae in wildlife, foodproducing, and companion animals: A systematic review. Clin. Microbiol. Infect. 24:1241-1250. https://doi. org/10.1016/j.cmi.2018.04.004

Kpoda, D. S., A. Ajayi, M. Somda, O. Traore, N. Guessennd, A. S. Ouattara, L. Sangare, A. S. Traore, \& Dosso, M. 2018. Distribution of resistance genes encoding ESBLs in Enterobacteriaceae isolated from biological samples in health centers in Ouagadougou, Burkina Faso. BMC Res. Notes. 11:471. https://doi.org/10.1186/s13104-018-3581-5

Liu, B. T., X. Y. Zhang, S. W. Wan, J. J. Hao, R. D. Jiang, \& F. J. Song. 2018. Characteristics of carbapenem-resistant Enterobacteriaceae in ready-to-eat vegetables in China. Front. Microbiol. 9:1147. https://doi.org/10.3389/fmicb.2018.01147

Lugsomya, K., J. Yindee, W. Niyomtham, C. Tribuddharat, P. Tummaruk, D. J. Hampson, \& Prapasarakul, N. 2018. Antimicrobial resistance in commensal Escherichio coli isolated from pigs and pork derived from farms either routinely using or not using in-feed antimicrobials. Microb. Drug Resist. 24:1054-1066. https://doi.org/10.1089/ mdr.2018.0154

Magiorakos, A. P., A. Srinivasan, R. T. Carey, Y. Carmeli, M. T. Falagas, C. G. Giske, S. Harbarth, J. F. Hindler, G. Kahlmeter, B. Olsson-Liljequist, D. L. Paterson, L. B. Rice, J. Stelling, M. J. Struelens, A. Vatopoulos, J. T. Weber, \& D. L. Monneta. 2012. Multidrug-resistant, extensively drug-resistant and pandrug-resistant bacteria: An international expert proposal for interim standard definitions for acquired resistance. Clin. Microbiol. Infect. 18:268-281. https://doi.org/10.1111/j.1469-0691.2011.03570.x

Meletis, G. 2016. Carbapenem resistance: Overview of the problem and future perspectives. Ther. Adv. Infect. Dis. 3:1521. https://doi.org/10.1177/2049936115621709

Mogheiseh, A., A. Derakhshandeh, S. Heidarifar, \& E. Bandariyan. 2020. Direct endoscopic lavage and biopsy sampling and evaluation of uterine microflora in various stages of the canine estrous cycle. Vet. Res. Forum. 11:89.

Nahar, A., S. P. Awasthi, N. Hatanaka, K. Okuno, P. H. Hoang, J. Hassan, A. Hinenoya, \& S. Yamasaki. S. 2018. Prevalence and characteristics of extended- spectrum $\beta$-lactamase-producing Escherichia coli in domestic and imported poultry meats in Japan. J. Vet. Med. Sci. 80:510-517. https://doi.org/10.1292/jvms.17-0708

Naas, T., G. Cuzon, P. Bogaerts, Y. Glupczynski, \& P. Nordmann. 2011. Evaluation of a DNA microarray (CheckMDR CT102) for rapid detection of TEM, SHV, and CTX-M extended-spectrum $\beta$-lactamases and of KPC, OXA-48, VIM, IMP, and NDM-1 carbapenemases. J. Clin. Microbiol. 49:1608-1613. https://doi.org/10.1128/JCM.02607-10

Rahman, S. U., S. Ahmad, \& I. Khan. 2018. Incidence of ESBLproducing-Escherichia coli in poultry farm environment and retail poultry meat. Pak. Vet. J. 39:116-20. https://doi. org/10.29261/pakvetj/2018.091

Ramos, S., V. Silva, M. D. L. E. Dapkevicius, M, Caniça, M. T. Tejedor-Junco, G. Igrejas, G, \& P. Poeta. 2020. Escherichia 
coli as commensal and pathogenic bacteria among foodproducing animals: Health implications of extended spectrum $\beta$-lactamase (ESBL) production. Animals 10:2239. https://doi.org/10.3390/ani10122239

Rasool, U., S. Priya, A. Parveen, S. K. Sah, \& S. Hemalatha. 2018. Efficacy of Andrographis paniculata against extended spectrum $\beta$-lactamase (ESBL) producing E. coli. BMC Complement. Altern. Med. 18:1-9. https://doi.org/10.1186/ s12906-018-2312-8

Rodríguez-Baño, J., B. Gutiérrez-Gutiérrez, I. Machuca, \& A. Pascual. 2018. Treatment of infections caused by extendedspectrum-beta-lactamase-, AmpC-, and carbapenemaseproducing Enterobacteriaceae. Clin. Microbiol. Rev. 31. https://doi.org/10.1128/CMR.00079-17

Sawa, T., K. Kooguchi, \& K. Moriyama. 2020. Molecular diversity of extended- spectrum $\beta$-lactamases and carbapenemases, and antimicrobial resistance. J. Intensive Care. 8:13. https://doi.org/10.1186/s40560-020-0429-6

Scott, H. M., G. Acuff, G. Bergeron, M. W. Bourassa, J. Gill, D. W. Graham, L. H. Kahn, P. S. Morley, M. J. Salois, S. Simjee, R. S. Singer, T. C. Smith, C. Storrs, \& T. E. Wittum. 2019. Critically important antibiotics: Criteria and approaches for measuring and reducing their use in food animal agriculture. Ann. N. Y. Acad. Sci. 1441:8. https:// doi.org/10.1111/nyas.14058

Suay-García, B. \& M. T. Pérez-Gracia. 2019. Present and future of carbapenem- resistant Enterobacteriaceae (CRE) infections. Antibiotics 8:122. https://doi.org/10.3390/ antibiotics 8030122

Tian, X., S. Sun, X. Jia, H. Zou, S. Li, \& L. Zhang. 2018 Epidemiology of and risk factors for infection with extended-spectrum $\beta$-lactamase-producing carbapenem- resistant Enterobacteriaceae: results of a double case-control study. Infect. Drug Resist. 11:1339. https://doi.org/10.2147/ IDR.S173456

Wang, Y., C. Wu, Q. Zhang, J. Qi, H. Liu, Y. Wang, T. He, L. Ma, J. Lai, Z. Shen, Y. Liu, \& J. Shen. 2012. Identification of New Delhi metallo- $\beta$-lactamase 1 in Acinetobacter lwoffii of food animal origin. PLoS ONE 7:e37152. https://doi. org/10.1371/journal.pone.0037152

Yassin, A. K., J. Gong, P. Kelly, G. Lu, L. Guardabassi, L. Wei, X. Han, H. Qiu, S. Price, D. Cheng, \& C. Wang. 2017. Antimicrobial resistance in clinical Escherichia coli isolates from poultry and livestock, China. PLoS ONE 12:e0185326. https://doi.org/10.1371/journal.pone.0185326

Zhang, B., Ku, X., Yu, X., Sun, Q., Wu, H., Chen, F., X. Zhang, L. Guo, X. Tang, \& Q. He. 2019. Prevalence and antimicrobial susceptibilities of bacterial pathogens in Chinese swine farms from 2013 to 2017. Sci. rep. 9:1-11. https://doi. org/10.1038/s41598-019-45482-8

Zhao, X., J. Yang, Z. Ju, W. Chang, \& S. Sun. 2018. Molecular characterization of antimicrobial resistance in Escherichia coli from rabbit farms in Tai'an, China. Biomed. Res. Int. 2018: 8607647. https://doi.org/10.1155/2018/8607647 